DOI 10.32370/2018_07_76

\title{
How to Increase the Efficiency of Teaching Calculus I at College Level: Student-Centered Approach
}

\author{
Anastasiya Yakunina, Ph.D. \\ Associate Professor of Mathematics \\ Voorhees College, 481 Porter Dr, Denmark, SC 29042 USA \\ anastasiya.yakunina@yahoo.com,ayakunina@voorhees.edu
}

\begin{abstract}
The article is dedicated to the problem of optimization of teaching Calculus I in a college. The most important factors that influence the efficiency of a teaching process (a composition of the class, students' background in Mathematics, correct choice of the assignments for the students, etc.) are presented. Concrete instructions for successful teaching Calculus I are given. Special attention is paid to a student-centered approach that is considered as a useful tool for an improvement of the results of teaching Mathematics at college level. All conclusions and recommendations are based on the results of modern research in Education and on the author's teaching experience (11years).
\end{abstract}

Keywords: Teaching Calculus, teaching Mathematics in college, individual approach, effective teaching, student-centered education

In the beginning of teaching Calculus I in college there're some important factors that you have to take into consideration if you want to succeed.

A composition of the class is one of them. Generally speaking, all students have different backgrounds in Mathematics. For example, some of them studied only Pre-Calculus, while the other students took one-year course of Calculus at high school. So if you have a miscellaneous composition of the class, it's always a good idea in the beginning of the study of the course to review the most important basic concepts not only of Calculus but of Pre-Calculus as well. Also you can give your students some tasks (tests, home assignments, etc.) to find out what their level of mathematical knowledge is. In accordance with the results you can plan and correct your teaching process, to render individual help and tutoring to the students who need it (not only at class but during your office hours as well).

An instructor should understand how important it is to maintain the students' interest at high level during a class session (this refers especially to teaching Mathematics but at the same time is more difficult to realize in practice than when teaching, for example, History). Review of the basic concepts can be boring for those students at your class who already know "all this stuff". A good solution of this problem is to make such students your helpers during class session. For example you can ask them to "remind" you of some useful formulas instead of 
writing them down by yourself. Of course even the best students sometimes make errors so you should be ready to correct them if needed. It's of the utmost importance to keep your students willing to assist you during the class, to make them actively involved into learning process. It's possible to attain only if an instructor is polite and friendly with his/her students. So if you encourage your students to help you during class and they made some errors, you should never criticize them rudely and don't allow other students in class to do it, because in this case the students (especially those of them who are shy) will lose their self-confidence and probably will never help you again, so you will "lose" them. Instead of accusation of the lack of knowledge, correct the student politely if he/she is wrong and at the end of the discussion thank the student for his/her help.

In accordance with the student-centered theory of teaching, maintaining a friendly, comfortable atmosphere during every class session is one of the essential factors that allow you to succeed in teaching not only Calculus but all disciplines [1].

In the beginning of a study of Calculus I it's essential to make your students understand how important it is for them to have well-developed skills of basic differentiation. You have to emphasize that studying Calculus I supposes good knowledge of the basic properties of differentiation so they won't succeed in Calculus I if they don't remember the most significant formulas for differentiation (of the product, quotient and the chain rule) and the formulas for differentiation of basic algebraic and transcendent functions.

So one of the important factors of successful teaching Calculus I is to dedicate 1-3 first lectures to remind your students of the basic properties of derivatives and of how to use them in practical differentiation [2].

Explain to your students that there can't be too much practice with differentiation. Give them as many examples and problems as possible (it will be much more effective if you ask your students to "help" you to solve them in class). Collective discussion is one of the most useful methods that can be applied here. Encourage your students to ask you any questions in the process of solution if they have them. Also you should ask your students if they need additional examples. When the problem is solved, don't forget to discuss a solution briefly once again and stress the key points of it to your students. The practice of teaching Calculus proves that it's more beneficial to solve only 5 problems but to explain them to the students thoroughly than to solve 10 problems quickly but without proper explanation [3]. 
Emphasize that you'll apply the formulas for differentiation throughout the entire course and that problems will become much more difficult very soon. Encourage your students to apply for help if they still don't feel that they mastered the basic differentiation of the functions. Don't study new stuff until you're sure that your students remember all the necessary formulas and can apply them quickly (almost automatically).

It's very helpful to give your students a test or a quiz after 1-3 introductory class sessions. If the students demonstrate sufficient understanding of the basis of differentiation, you can start to study the formal definition of the limit. Actually it's not necessary to require memorizing this definition because it's quite difficult and many students will forget it sooner or later. It's probably more useful to give your students some graphic examples of the limits of the functions, to show the difference between $\lim _{x \longrightarrow a-0} f(x), \lim _{x \longrightarrow a+0} f(x)^{\prime} f(a) \underset{\text { and }}{\lim _{x \longrightarrow a} f(x)}$ (consider different cases).

Also solve some quick problems for the limits of the following types: $m / 0,0 / m, \infty / \infty$, $0 / 0,0 / \infty, \infty / 0$ ( $m \in \mathrm{R}, m \neq 0 ; m$ can be any real number, e.g. you can use 1 for $m$ ). Don't be too concerned about the application of the strict definition of the limit but rather try to help your students to understand the gist of the matter. Such problems are not only interesting for students, they really help to develop their logic and mathematical intuition as well.

For many students Calculus I is more difficult discipline than Pre-Calculus, therefore it's very important to make sure that your students really understand the stuff that you teach. Mathematics is quite complex discipline, and just memorizing formulas, definitions and algorithms never brings good results if the students don't have a true understanding of learning material.

So, it's very beneficial to give your students tests and quizzes after they studied every important concept. Of course a teacher must keep a sense of proportion about assignments. For instance, some instructors give tests to their students in every other class session that is timeconsuming and stressful for many students. One quiz per 4-5 class sessions is usually quite enough to get a sufficient feedback.

Alongside with quizzes and tests during class you can ask your students some quick questions about the stuff that they're currently studying just to make sure that they pay attention to your lecture and that they understand the learning material correctly. It's a very effective 
practice because it provides an instant feedback and you can correct your teaching immediately (e.g. you can give your students some additional explanations and examples). Furthermore asking quick questions during class doesn't take much time; it's usually interesting for students, really involves them into learning activity and isn't very stressful for them.

A practice of teaching Calculus I shows that an instructor should not rely on the results of homework too much because you never can be sure that the student accomplished it himself. Often students ask their friends and classmates to help them with homework. It refers especially to the students with poor background in Mathematics who actually need your help more than others, so homework hardly can provide a valid feedback. It's better to consider homework just as an additional practice for your students.

So we discussed some important factors that an instructor has to take into consideration to teach Calculus I successfully. One of the exciting opportunities for any instructor is not only to teach Mathematics but to learn HOW to teach!

\section{References}

1. Friedberg, Solomon. Teaching Mathematics in Colleges and Universities: Case Studies for Today's Classroom / Student ed. Conference Board of Mathematical Sciences, Rhode Island. 2001.

2. Kelton, Suzanne. An Introduction to Teaching Mathematics at the College Level / Assumption College. Available: https://www.ams.org/profession/career-info/gradschool/Kelton-TEACH.pdf

3. Krantz, Steven. How to Teach Mathematics. $3^{\text {rd }}$ edition. American Mathematical Society, Rhode Island, 2015, P. 26. 